\title{
Pancreatic Tuberculosis mimicking Cystic Neoplasm
}

\author{
Anamika Jha \\ MD, Lecturer, Department of Radiology, IOM, TU Teaching Hospital, Maharajgunj, Kathmandu, Nepal.
}

Correspondence: Anamika Jha, Lecturer, Department of Radiology, IOM, TU Teaching Hospital, Maharajgunj, Kathmandu, Nepal.

Email: dranamikakasyap@gmail.com

\begin{abstract}
Tuberculosis is endemic in our part of the world and may have uncommon presentations like pancreatic involvement. A young male presented to the OPD with recent history of pain in epigastric region and was subsequently diagnosed with a multi-loculated cystic neoplasm in pancreatic head region on ultrasonography and $\mathrm{CT}$ scan. The pancreatic origin was confirmed on surgery while the histopathological study revealed tuberculous nature. This case report highlights the importance of considering tuberculosis in the differential diagnosis in pancreatic masses, especially, with atypical appearances, in young patients or with background predisposing to TB and the need for histological diagnosis.
\end{abstract}

Keywords: Pancreatic tuberculosis, Cystic pancreatic lesion.

\section{Introduction}

Abdomen is a common site of extrapulmonary TB involvement although pancreatic involvement is uncommon with unknown true incidence. ${ }^{1}$ It usually occurs as a complication of miliary tuberculosis, exaggerated by immunodeficiency and it may be the only site of reactivation in later years. Clinical and imaging features are also similar to other pancreatic neoplasms and so diagnosis is often missed before laparotomy.,3 We present a rare case of isolated pancreatic tuberculosis in a young male that mimicked cystic pancreatic neoplasm.

\section{Case report}

A 21 years old male patient, presented to the OPD with history of pain in right upper quadrant and epigastric region for 20 days with loss of appetite with past history of treatment for bone tuberculosis 16 years back. Blood examination including amylase were normal except raised liver enzymes particularly Alkaline Phosphatase. The ultrasound revealed a complex cystic lesion with lobulated outline and septations in the pancreatic head region causing abrupt obliteration of distal CBD (common bile duct) with proximal obstructive biliopathy (Figure 1). Gall Bladder was distended with sludge. CT scan findings were a cystic mass $6 \times 4 \times 4.8 \mathrm{~cm}$ in size with enhancing walls and septae, involving the pancreatic head with exophytic component supero-medial to the duodenal C-loop, encasing the distal CBD with proximal biliopathy and distended gall bladder (Figure 2). This lesion was indenting on the main portal vein without any thrombus and abutting the caudate lobe of liver with loss of fat planes (Figure 3). Rest of the pancreas and main pancreatic duct were normal. These findings were suggestive of complex cystic pancreatic head tumor.

Peroperatively, the tumor origin from the pancreatic head was confirmed and it was seen to be infiltrating into the distal $\mathrm{CBD}$ and main portal vein. An enlarged lymph node was present at common hepatic artery level. Decompression and partial tumor resection was done with hepaticojejunostomy. Histopathological report confirmed the lesion to be tuberculous, with the excised lymph node showing benign lymphoid tissue, gall bladder showing inflammatory changes and unremarkable CBD (Figure 4). Final diagnosis of pancreatic head TB was made and the patient started on ATT to which he showed good response. 


\section{Discussion}

Abdominal TB is a common site of extra pulmonary TB and has four forms, most common being involvement of lymph nodes followed by intestines, peritoneum and rarely solid organs. ${ }^{1}$ Pancreas is believed to be resistant to seeding by $M$. tuberculosis by virtue of pancreatic enzymes and is involved in about $0-4.7 \%$ of TB cases. ${ }^{4}$ The modes of involvement of pancreas may be haematogenous, direct spread from adjacent lymph node or organs, lymphatic or reactivation of dormant focus. Pancreatic TB has predilection for involving pancreatic head probably due to its dual vascular supply.

Clinically, both pancreatic malignancy and tuberculosis may have similar presentations like weight loss, anorexia, abdominal pain, obstructive jaundice, etc. Additionally, the radiological appearances of pancreatic malignancy and TB may be similar with peripancreatic lymphadenopathy in both. In the absence of ancillary findings like pulmonary tuberculosis, pleural effusion, mural thickening in the ileocecal region, lymphadenopathy with peripheral ring enhancement, diagnosis of TB remains elusive. Few reports of pancreatic TB are there in literature, most of which presented as pancreatic mass only some of which were diagnosed pre-operatively with FNAC and most post-operatively. 5 ,6 Similarly, Saluja et al, retrospectively reviewed the records of 18 patients over two decades, with proven histological diagnosis of hepatobiliary and pancreatic tuberculosis. Of these 7 patients were found to have pancreatic and peri-pancreatic tuberculosis of which only 3 were diagnosed pre-operatively. ${ }^{2}$

Pancreatic TB on ultrasonogram, may appear as focal hypoechoic or cystic lesions in the pancreatic head. CT scan findings most commonly reveal a solid or cystic mass lesion in pancreatic head region with peripancreatic lymphadenopathy. ${ }^{7}$ De Backer AI et al, studied MR appearance of pancreatic TB and found it to be hypointense on T1 fat saturated sequences (compared with normal pancreatic tissue), heterogenous on T2 sequences and multiloculated appearance with peripheral enhancement on post contrast sequences. ${ }^{8}$

The potential risk of needle track seeding and tumor dissemination prevents the physicians to perform FNA. ${ }^{9}$ However, as there are no clinical, laboratory or radiological features specific for pancreatic $\mathrm{TB}$, vigorous histopathological, cytological and bacteriological confirmation should be considered in select patients in view of alternate diagnosis which may avert a major surgery and in all inoperable lesions of pancreas. Mallery et al, found similar accuracy of EUS-guided, CT/US-guided FNA and surgical tissue sampling of the pancreatic lesions. ${ }^{10}$

To summarize, pancreatic TB should be considered in the differential diagnosis of a pancreatic lesion, especially with atypical imaging appearance, for young people, in endemic areas and in immune compromised conditions. Such cases should be subjected to image guided FNA for pathological/ bacteriological diagnosis which may avoid a major surgery in favor of medical treatment to which the response is good.

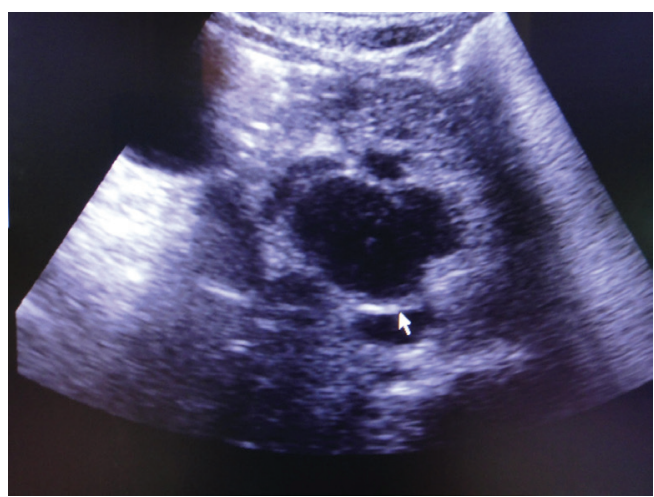

Figure 1: Ultrasound showing the complex cystic mass in pancreatic region
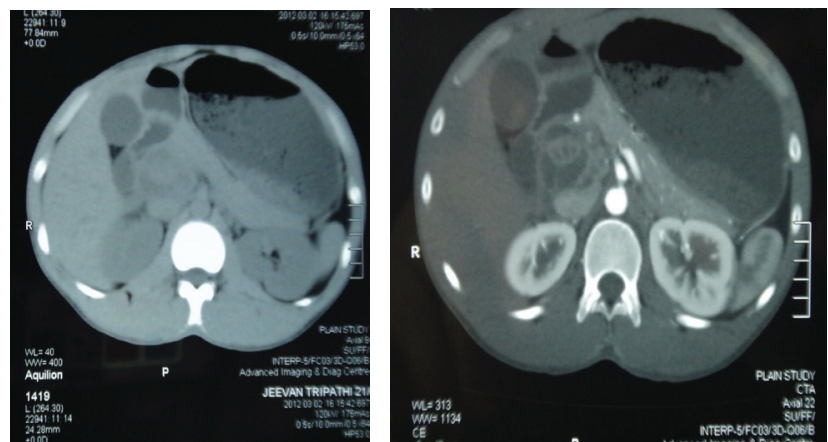

Figure 2. Axial images plain \& contrast enhanced CT scan showing cystic pancreatic head lesion with enhancing wall $\&$ septation. 


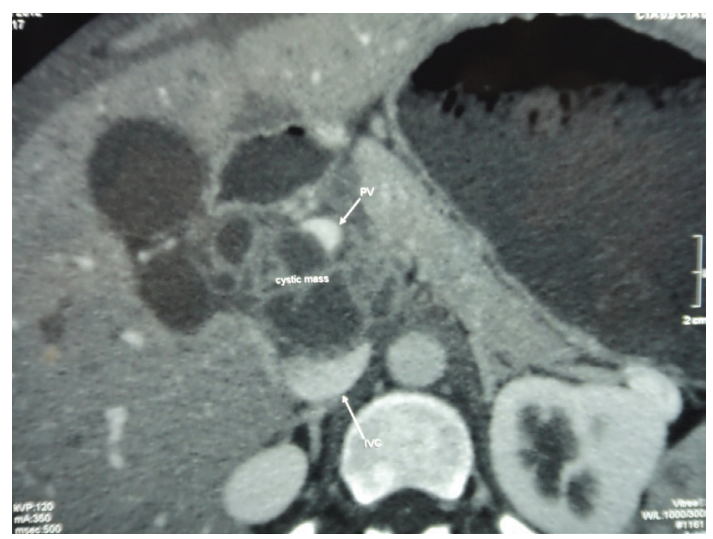

Figure 3. Axial CECT image showing narrowed Main Portal vein.

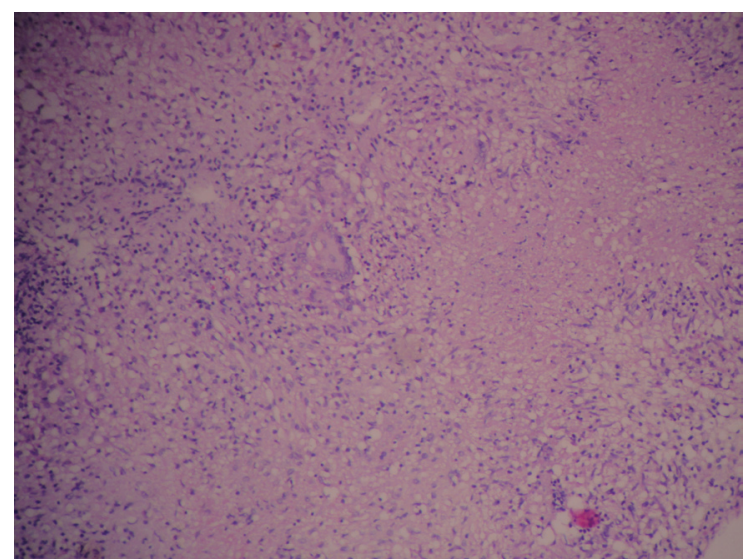

Figure 4. Photomicrograph showing extensive caseous necrosis (arrow) surrounded by epithelioid cells, Langhan's type of giant cells (arrow head) and scattered lymphocytes (HE stain, x10)

\section{References}

1. Debi U, Ravisankar V, Prasad KK, Sinha SK, Sharma AK. Abdominal tuberculosis of the gastrointestinal tract: Revisited. World J Gastroenterol. 2014 Oct 28; 20(40): 14831-14840. https://doi.org/10.3748/wjg.v20.i40.14831 PMid:25356043 PMCid:PMC4209546

2. Saluja SS, Ray S, Pal S, Kukaraja M, Srivastava DN, Sahni P, Chattopadhyay TK. Hepatobiliary and pancreatic tuberculosis: a two decade experience. BMC Surg 2007; 7:10. https://doi.org/10.1186/1471-2482-7-10 PMid:17588265 PMCid:PMC1925057
3. Desai DC, Swaroop VS, Mohandas KM, Borges A, Dhir $\mathrm{V}$, Nagral A, et al. Tuberculosis of the pancreas: report of three cases. Am J Gastroenterol 1991; 86:761-3. PMid:2039002

4. Auerbach O. Acute generalized miliary tuberculosis. Am J Pathol 1944; 210:121-36.

5. Chaudhary A, Negi SS, Sachdev AK, Gondal R. Pancreatic tuberculosis: Still a histopathological diagnosis. Dig Surg 2002; 19: 389-92. https://doi.org/10.1159/000065832 PMid: 12435910

6. Pramesh CS, Heroor AA, Gupta SG, Krishnamurthy S, Shukla PJ, Jagannath P, Dsouza LJ. Pancreatic Tuberculosis: an elusive diagnosis.

7. Pombo F, Diaz-Candamio MJ, Rodriguez E, Pombo S. Pancreatic tuberculosis: C T findings. Abdom Imaging. 1998;23: 394-7. https://doi.org/10.1007/s 002619900367 PMid:9663275

8. De Backer AI, Mortele KJ, Bomans P, De Keulenaer BL, Vanschoubroeck IJ, Kockx MM. Tuberculosis of the pancreas: MRI features. AJR Am J Roentgenol 2005; 184:50-4. https://doi.org/10.2214/ajr. 184.1 .01840050 PMid: 15615950

9. Shyamala K, Girish HC, Murgod S. Risk of tumor cell seeding through biopsy and aspiration cytology. J Int Soc Prev Community Dent. 2014 Jan-Apr; 4(1): 5-11. https://doi.org/10.4103/2231-0762.129446 PMid:24818087 PMCid:PMC4015162

10. Mallery JS, Centeno BA, Hahn PF, Chang Y, Warshaw AL, Brugge WR. Pancreatic tissue sampling guided by EUS, CT/US, and surgery: a comparison of sensitivity and specificity. Gastrointest Endosc. 2002 Aug; 56(2):218-24. https://doi.org/10.1016/S0016-5107(02)70181-8 